\title{
ПОЖКИЛЫЕ В РОССИЙСКОЙ НЕГОСУДАРСТВЕННОЙ СОЦИАЛЬНОЙ РАБОТЕ
}

Анализируются изменения социальной политики и социальной работы в отношении граждан старшего возраста. Анализ сфокусирован на трансформации социальной работы с пожилыми в последние четыре года в связи с актуализацией договорных отношений в социальном обслуживании и участии социально ориентированных некоммерческих организаций в конкурсе на государственные субсидии. Изучение негосударственной социальной работы в отношении пожилых проведено с помощью комплекса исследований, включая контент-анализ экспертных интервью представителей религиозных организаций об оказании ими социальных услуг (N=59) с 2008-2013 гг; анкетирование населения Нижнего Новгорода по квотной выборке (N=1976) в 2013-2014 гг.; обобщение бесед об учете религиозных потребностей клиентов в оказании социальных услуг в государственных социальных учреждениях $(\mathrm{N}=53)$ в 2015-2016 гг., наблюдения авторов за оказанием социальной помощи пожилым религиозными организациями Нижнего Новгорода, Москвы, Украины и Германии последние 20 лет. По данным исследования, ожидания пожилых в отношении социальных услуг государственных учреждений и религиозных организаций ориентированы на пассивное получение помощи. Эксперты религиозных организаций конструируют пожилых клиентов в терминах получателей помощи, игнорируя их ресурсность и возможность активизации. Отмечено неравномерное отставание идеологии социальной работы от ориентиров

Зарэтхан Хаджи-Мурзаевна Саралиева - д.и.н., доцент, зав. кафедрой отраслевой и прикладной социологии и социальной работы Национального исследовательского Нижегородского государственного университета им. Н. И. Лобачевского, Нижний Новгород, Россия. Электронная почта: zara@fsn.unn.ru

Ирина Эдуардовна Петрова - к.с.н., доцент кафедры общей социологии и социальной работы Национального исследовательского Нижегородского государственного университета им. Н.И. Лобачевского, Нижний Новгород, Россия. Электронная почта: irinapetrova@mail.ru 
социальной политики. Основной вид деятельности государственных учреждений - формирование регистра получателей и осуществление социальных услуг. Некоммерческие светские социальные организации демонстрируют гораздо больший ассортимент социальных услуг и готовы к внедрению инноваций. Религиозные организации традиционно относят пожилых к клиентам социальной работы и ориентируют их на пассивное получение помощи.

Ключевые слова: пожилые, социальная политика, социальная работа, социально ориентированные некоммерческие организации, религиозные организации

DOI: $10.17323 / 727-0634-2018-16-1-95-108$

Трансформация государственной социальной политики от патернализма к поддержке активности граждан старшего возраста стала предметом пристального внимания российских ученых (Саралиева, Балабанов 1999; Григорьева 2005a, 2005b). Каждый новый шаг (принятие концепции, утверждение и реализация федеральной целевой программы, изменение законодательства) анализировался, и после 25 лет внедрения этой политики исследователи делают выводы о ее эффективности и дальнейших перспективах. Переход от пассивного ожидания помощи от государства к ориентации на собственные ресурсы пожилое население России демонстрирует в 1990-е гг. Многочисленные социологические исследования показывали разочарование пожилых в жестких мерах социальной политики государства и постепенное осознание необходимости рассчитывать на собственные силы. Как подчеркивали авторы, социальная политика в отношении старшего поколения должна быть направлена на обеспечение экономической независимости и предоставление равных условий для полноценного участия во всех сферах жизни и видах активности (Саралиева, Балабанов 1999: 64).

Формирование рынка социальных услуг для старшего поколения происходило со значительными трудностями. Вызвано это было как необходимостью изменения социальной политики государства, так и отношением населения к социальному обслуживанию в целом и к платным услугам, в особенности. После проведения «монетизации льгот» в 2004 г. Ирина Григорьева дала оценку сложности и дороговизны перехода от универсальной системы социального обслуживания к адресной помощи, а также неприятия платных социальных услуг пожилыми клиентами, которые воспринимали это как оскорбление (Григорьева 2005a, 2005b).

Два десятилетия развития социальной политики в отношении старшего поколения россиян сформировали новые правовые концепции оказания социальных услуг пожилым. В качестве основных необходимо выделить децентрализацию предоставления социальных услуг (введение индивидуальных предпринимателей и НКО в качестве поставщиков социальных услуг), а также 
наделение самих пожилых правом выбора услуги в ранге ее получателя. Негосударственная социальная работа в России легитимизируется таким образом, а дальнейшие перспективы развития социальной политики в интересах пожилых формулируются именно с учетом возможностей НКО и бизнеса в этой сфере услуг. Поэтому важно изучить развитие негосударственной социальной работы с пожилыми с точки зрения формирования новых правовых, социальных и религиозных концепций социальной работы.

\section{Социальное обслуживание пожилых: трансформация идеологии в праве}

Современные правовые положения о предоставлении социальных услуг пожилым сформулированы в Концепции долгосрочного социально-экономического развития Российской Федерации на период до 2020 г. (Распоряжение Правительства РФ 2008). В разделе, посвященном развитию социальных институтов и социальной политики, в качестве четвертого направления совершенствования представлено социальное обслуживание граждан старших возрастов и инвалидов. Согласно закону, в социальной работе введены договорные отношения между поставщиком социальной услуги и ее получателем.

В Стратегии действий в интересах граждан старшего поколения в Российской Федерации до 2025 г. (Распоряжение Правительства РФ 2016) выделены приоритетные направления реализации социальной политики в отношении пожилых. Направление, связанное с «развитием современных форм социального обслуживания», включает в себя «модернизацию организаций социального обслуживания, актуализацию перечня дополнительных социальных услуг» (Распоряжение Правительства РФ 2016:28). В частности, оно ориентирует исполнителей Стратегии на «увеличение количества негосударственных организаций и индивидуальных предпринимателей, предоставляющих услуги по социальному обслуживанию граждан старшего поколения» (Распоряжение Правительства РФ 2016:29).

Конструирование образа пожилого в правовом обеспечении социальной работы в последнее время претерпевает важные изменения. Основными обязанностями получателя услуги, согласно Ф3 «Об основах социального обслуживания граждан», становятся передача компетентным органам власти «сведений и документов, необходимых для предоставления социальных услуг; своевременное информирование поставщиков социальных услуг об изменении обстоятельств, обусловливающих потребность в предоставлении социальных услуг; а также соблюдение условий договора о предоставлении социальных услуг» (Федеральный закон 2013: Ст. 10).

Согласно статье 26 этого закона, основной деятельностью по организации социального обслуживания со стороны региональных министерств и ведомств является ведение реестра поставщиков и регистра получателей 
социальных услуг. Система казенных и бюджетных центров социального обслуживания населения сосредоточена на выполнении обязательств по отношению к получателям услуги, является структурно-функциональной и мало подходит для привлечения и внедрения различных инноваций. Пожилой получатель услуги может рассчитывать на удовлетворение различных потребностей, но только в рамках существующего образа пассивного клиента. Казалось бы, можно было считать шагом вперед введение категории получателя социальных услуг, но в реальности утверждается субъект-объектная парадигма социальной работы, так как механизмов повышения активности клиента на уровне закона не сформировано.

\section{Негосударственная социальная работа для пожилых}

Правовые инициативы часто подвергаются анализу, в процессе которого вырабатываются новые подходы к регулированию социальной работы. Развитию социальной работы с пожилыми и внедрению инноваций в сфере оказания социальных услуг людям третьего возраста посвящено значительное число научных публикаций. Их темами становятся развитие инновационных моделей предоставления услуг, активное участие пожилых в совершенствовании социальных сервисов, а также опыт, риски и затруднения НКО в качестве акторов социальной работы. При этом анализ социальной политики в этой области проводится как на международном, так и на локальном уровне.

Например, коллектив авторов в докладе о странах Центральной Европы исследует включение НКО в систему социального обслуживания (Pfeiferová et al. 2013). В качестве принципов отбора лучших практик социальной работы с пожилыми авторы отмечают, в первую очередь, участие пожилых в разработке и внедрении социальных услуг для себя. Ученые делают ожидаемый вывод о том, что инновационные схемы предоставления социальных услуг требуют большего личного участия сотрудников сервисов, их лучшей подготовленности и значительного объема ресурсов на посредничество между клиентами и службами. В России одним из важных способов участия НКО в оказании помощи пожилым стала независимая оценка работы государственных учреждений социального обслуживания. Такой опыт представлен деятельностью Общественного совета некоммерческих организаций Санкт-Петербурга (Бодановская, Гольдман 2015).

Анализ специфики участия российских НКО в социальной работе с пожилыми представляет Артур Холявин (2015), основное внимание уделяя типологизации НКО. Один тип автор условно называет «grass-root» и относит к ним инициативные организации. Второй тип - НКО-«клиентелы», по мнению Холявина, представлен формализованными объединениями граждан, созданными в тесном сотрудничестве с государством (например, союзы ветеранов). Холявин представляет значимые различия в деятельности 
организаций разной направленности. НКО-клиентелы как прогнозируемые стабильные прогосударственные участники допущены к процедурам обсуждения проблем и принятия решений, в то время как НКО из пула grassroot, как правило, не воспринимаются госорганами как полноправные участники этого процесса. Однако именно второй тип НКО становятся «основными источниками креативности, разработки неформальных подходов к образованию населения, помощи пожилым людям в организации их «проекта» старения» (Холявин 2015: 148). Автор отмечает, что представители первого и второго типа НКО редко взаимодействуют друг с другом: зачастую НКО-клиентелы становятся фасилитаторами государственной политики, тогда как вторые чаще обращают внимание государственных органов на нерешенные проблемы пожилых.

Оценку социальной работы ведут и сами органы власти. Согласно аналитическому докладу Минтруда России, субъектами Российской Федерации в реестр поставщиков социальных услуг на начало 2016 г. включено около 300 негосударственных организаций в 63 регионах (Минтруда РФ 2016). Это интерпретируется как высокая интенсивность работы между НКО и государством. Вместе с тем оценка самими представителями НКО возможностей работы в рамках государственных субсидий оценивается неоднозначно. В подборке интервью, собранных аналитиками Агентства социальных инициатив в Кемеровской области (где работает более 130 организаций из указанного выше реестра), представители НКО и бизнеса отмечают основные проблемы своей работы: «Постоянно экономим, работаем на энтузиазме без какого-либо дохода» (АСИ 2016). Условия существования НКО в реестре поставщиков социальных услуг могут быть затруднительными: требование оформлять огромное количество документов каждый год для вхождения в реестр; невысокие тарифы оплаты услуг со стороны государственных органов; необходимость документально подтверждать каждое действие в рамках оказания услуги (АСИ 2016); завышенные, по мнению представителей НКО, государственные стандарты при вступлении в реестр; проблема с возвратом средств за уже произведенные услуги; недостаточность информации, предоставляемой местными органами власти при запросах от НКО (Рондик 2015).

Во многих случаях предоставляемая индивидуальным предпринимателем социальная услуга расценивается как не подходящая под стандарт, и поэтому не субсидируется, как, например, повышение компьютерной грамотности на дому в Московской области (Лянгасов 2015). Несмотря на возможности, обеспеченные законодательством, многие субъекты РФ не спешат расширять реестр поставщиков социальных услуг за счет представителей бизнеса и НКО. Во многих регионах реестры представлены в подавляющем большинстве казенными и бюджетными ведомственными социальными учреждениями, которые меньше всего ориентированы на активизацию своих пожилых клиентов. 
Процедура вхождения в реестр, проведения конкурса на реализацию государственной субсидии и отчетность в качестве поставщика социальной услуги становится высоким барьером на пути многих негосударственных организаций. Субсидия не всегда соответствует затратам на оказание услуги, и сами негосударственные поставщики неоднозначно оценивают свои возможности продолжения социального бизнеса. Как правило, жесткие требования формирования реестра поставщиков социальных услуг препятствуют инновационному развитию социальной работы с пожилыми. В таких условиях негосударственная социальная работа с пожилыми скорее направлена на формирование пассивного пожилого клиента, нежели на инновационную деятельность и активизацию получателя услуги.

Относительно мало исследований раскрывают роль религиозных организаций, занятых социальной поддержкой в России. Радик Садыков дает анализ предоставления социальных услуг некоммерческими организациями, в том числе и религиозными. Исследователь подчеркивает гибкость формирования социальных сервисов в негосударственном секторе, учет потребностей таких категорий клиентов, которые традиционно исключены из получателей государственной помощи либо существенно ограничены в доступе к ней (Садыков 2015). Наше исследование позволяет подробнее описать деятельность религиозных организаций в области социальной работы.

\section{Социальная работа религиозных организаций}

Социальная работа религиозных организаций в современной России демонстрирует признаки профессионализации. Здесь складываются отличия от светской социальной работы как государственных учреждений, так и НКО. Формирование клиентелы, адаптация разных подходов, значимость религиозности клиента, социального работника и жизни общины приобретают важное значение в дальнейшем развитии социальной работы в рамках разных конфессий. В нескольких субъектах РФ в реестр поставщиков с 2014 г. входят религиозные организации - например, в Татарстане приблизительно равное количество православных и мусульманских, оказывающих социальные услуги в основном пожилым. В областях центральной России поставщики социальных услуг из числа религиозных общин в основном представлены православными организациями (АСИ 2016).

В чем специфика работы таких организаций в качестве поставщиков социальных услуг? Ростислав Кононенко выявляет противоречия, с которыми сталкиваются социальные работники на приходах. Одним из самых значимых становится противоречие между религиозной моралью, которая требует оказать помощь всем нуждающимся, и неолиберальной установкой на проверку подлинности нуждаемости клиента (Кононенко 2013). Превалирующим религиозным учением при этом является доктрина РПЦ, которая организует социальную работу наиболее активно в России. 
Так, православная служба «Милосердие» является одной их самых ранних и наиболее успешных негосударственных социальных организаций. Создана в начале 1990-х гг. по инициативе иерея Аркадия Шатова, ныне епископа Орехово-Зуевского Пантелеимона и руководителя Синодального отдела по церковной благотворительности и социальному служению. Именно он в настоящее время представляет на различных публичных площадках идеологию церковной социальной работы РПЦ.

По мнению сотрудников службы «Милосердие», правильное отношение к просителю является базовым условием эффективного оказания помощи. Большая часть пособия «Как помогать просителям: работа церковной социальной службы» посвящена классификации запросов и способов поведения клиентов, выполненная на богатом опыте службы «Милосердие», и зачастую эта типология не совпала бы с описанием клиентелы светской социальной работы (Любезнова и др. 2015). Можно выделить значимые различия в используемых конструктах клиента и подходах к реализации социальной работы в религиозных организациях и государственных учреждениях. Представляется, что социальная работа религиозных организаций направлена на изменение жизни клиента, которое связано с принятием религиозного подхода к разрешению проблем, а также интеграцию в жизнь общины и взаимодействие с церковным социальным работником.

В стратегиях развития социальных сервисов российских религиозных организаций имеются некоторые различия. НКО, представляющие наиболее распространенные конфессии, могут быть рассмотрены как НКО-клиентелы (Холявин 2015) - они допущены к процессу принятия решений вместе с государственными органами - и могут лоббировать интересы своих служб и клиентов. Остальные религиозные НКО вынуждены работать в режиме местной инициативы без доступа к значительным ресурсам и координации с госорганами. В настоящее время внедрение инноваций и адаптация зарубежного опыта больше доступны крупным конфессиональным НКО, поддерживаемым государством.

\section{Пожилые клиенты}

\section{В понимании конфессиональных экспертов}

В период с 2008 по 2013 гг. авторами были собраны материалы опубликованных интервью и проведены исследовательские интервью со священнослужителями и работниками социальных отделов религиозных организаций $(\mathrm{N}=59)$. Интервью в среднем длилось около 1 часа. Для обработки полученных данных применен метод контент-анализа с использованием специализированного пакета ЛЕКТА. Базовый словарь составил более 38 тыс. слов. В результате получено 18 факторов, объясняющая способность модели $25 \%$.

Значимыми темами обсуждения стали выбор и обоснование проблем и клиентелы социальной работы религиозных организаций. Фактор «Клиенты и их потребности» включает в себя 331 цитату, в основном посвященных 
людям и проблемам, с которыми работают сотрудники церквей и других религиозных учреждений. В факторе преобладают цитаты из интервью представителей РПЦ, что подтверждает направленность на социальную работу в православных учреждениях и меныший опыт в этом других религиозных деноминаций. Выбор аудиторий и того, какие проблемы будут решаться, обосновываются богословской риторикой, а актуальная социальная ситуация позволяет расставить соответствующие акценты. Кроме того, на этот выбор влияет ресурсность организации.

Самой обычной категорией клиентов являются пожилые люди: «B Coюзе баптистов развита внутренняя диакония - забота о пожильх, стариках, многодетных семьях» (РС ЕХБ ${ }^{1}$, Москва, мужчина, служитель, 2012 г.). При этом пожилой клиент понимается как пассивный получатель помощи, о котором надо заботиться и которому следует помогать. Нет практически ни одного интервью, где пожилые получатели помощи наделялись бы полномочиями в использовании своего накопленного социального капитала. Часто социальная помощь церкви сопряжена с религиозными задачами:

Первым направлением деятельности стала работа с престарелыми - это патронажная помощь на дому, духовные беседы о православных праздниках и святых (РПЦ, Ростов-на-Дону, женщина, сотрудница церковной службы, 2012 г.)

Пожилые священнослужители, вдовые матушки, бездомные, одиноко проживающие и хронически больные пожилые оказываются основными клиентами помощи. В интервью о них говорят в терминах пассивных потребителей услуг.

\section{Отношение пожилых}

\section{к социальной работе религиозных организаций}

В период с ноября 2013 по февраль 2014 гг. в Нижнем Новгороде при поддержке факультета социальных наук Нижегородского государственного университета им. Н.И. Лобачевского разработан инструментарий и проведено исследование, направленное на выяснение отношения населения города к деятельности религиозных организаций и учреждений социального обслуживания в оказании социальных услуг. Отобрана 41 религиозная организация с учетом разнообразия зарегистрированных церковных организаций по направлениям вероучения. Проведено анкетирование жителей в Нижнем Новгороде по квотной репрезентативной для населения города по полу и возрасту (от 18 лет) выборке (1976 респондента). Ошибка выборки составляет 3 \%. Цель опроса - мнение населения о социальной

\footnotetext{
${ }^{1}$ Российский союз евангельских христиан-баптистов - централизованная религиозная организация, объединяющая поместные церкви (местные общины) евангельских христиан-баптистов на территории Российской Федерации.
} 
работе религиозных организаций. Опрашиваемым предложены 39 вопросов, из них 30 закрытых и 9 открытых.

Приведем ответы на закрытый вопрос «Как Вы оцениваете реальное влияние российских религиозных организаций на социальную ситуацию в стране?». Ответы мужчин и женщин мало различаются между собой (Табл. 1).

Таблицча 1

Оценка населением реального влияния российских религиозных организаций на социальную ситуацию в стране (в \% от числа опрошенных)

\begin{tabular}{lccc}
\hline & $\begin{array}{c}\text { В целом } \\
\text { по выборке, }\end{array}$ & Возраст до 55 & Пожилье \\
\hline Оказывают существенное влияние & 13 & 13 & 16 \\
Оказывают некоторое влияние & 51 & 51 & 53 \\
Практически не оказывают влияния & 25 & 27 & 20 \\
Не влияют & 10 & 9 & 11 \\
\hline
\end{tabular}

Респонденты возрастных групп старше 55 лет объединены в процессе исследования в подгруппу «Пожилые», которые демонстрируют существенную неоднородность оценок по некоторым позициям (Табл. 2). Более пожилые люди значимо резко отрицают реальные возможности религиозных организаций, вероятно, в силу сохранившихся атеистических взглядов.

\section{Оценка реального влияния российских религиозных организаций на социальную ситуацию в стране (в \% от числа опрошенных)}

\begin{tabular}{|c|c|c|c|c|c|c|c|c|c|}
\hline & \multicolumn{8}{|c|}{ Возраст респондента, лет } & \multirow{2}{*}{ 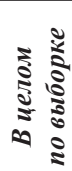 } \\
\hline & $\stackrel{\substack{1 \\
\vdots}}{\vdots}$ & 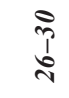 & $\frac{n}{n}$ & $\frac{2}{1}$ & in & $\begin{array}{l}n \\
b \\
1 \\
b \\
i n\end{array}$ & $\underset{\substack{n \\
b}}{b}$ & $\stackrel{8}{i}$ & \\
\hline $\begin{array}{l}\text { Оказывают существенное } \\
\text { влияние }\end{array}$ & 7 & 15 & 14 & 14 & 16 & 17 & 14 & 16 & 13 \\
\hline $\begin{array}{l}\text { Оказывают некоторое } \\
\text { влияние }\end{array}$ & 51 & 46 & 54 & 51 & 53 & 53 & 54 & 51 & 51 \\
\hline $\begin{array}{l}\text { Практически не оказывают } \\
\text { влияния }\end{array}$ & 32 & 27 & 24 & 27 & 21 & 25 & 17 & 17 & 25 \\
\hline Не влияют & 10 & 12 & 8 & 8 & 10 & 5 & 15 & 16 & 10 \\
\hline
\end{tabular}

По мере того как сокращается доход семьи, уменьшается уверенность в реальности влияния религиозных организаций на социальную ситуацию страны. Можно предположить, что именно малообеспеченные респонденты 
ожидают помощь больше, чем другие, и не получают ее. Пожилые склонны обращать большее внимание на социальные проблемы, актуальные в их возрасте - расходы на здравоохранение, вопросы ЖКХ в противовес меньшему интересу к развитию культуры.

Пожилые люди на вопрос о том, насколько активно религиозные организации должны оказывать помощь различным группам клиентов, с одной стороны, дают ответы, схожие с ответами остальных возрастных групп, но расставляют иные акценты. Более всего, по их мнению, социальные услуги должны быть предоставлены бедным (64\% в возрастах младше 55 лет и $68 \%$ среди пожилых), инвалидам (63\% и 66\% соответственно), бездомным (46\% в среднем по указанным двум группам) и, в особенности, пожилым (60\% и $68 \%$ ). В отношении пожилых, как мы видим, мнения представителей разных возрастов расходится чаще. Сами пожилые в большей степени хотели бы активной помощи со стороны религиозных организаций для себя и своих ровесников. Это заметно в ответах более старших возрастных групп выборки (65\% - респонденты от 56 до 65 лет, $71 \%$ - от 66 до 75 лет, и $70 \%$ - от 76 до 90 лет). Создается впечатление склонности пожилых респондентов к пассивному восприятию помощи и социальных услуг от религиозных организаций.

Пожилые склонны отдавать предпочтение социальным услугам религиозных организаций по позициям «Сострадание» и «Любовь к людям», но чаще доверяют государственной социальной работе в вопросах профессионального образования и доступности. Кроме того, возникает значимая разница в их оценке различных видов социальных услуг, которые они получают или могли бы получить в религиозных организациях и в государственных учреждениях. Социальную услугу (по действующему стандарту) пожилые оценивают одинаково, а вот в социально-экономической отдают абсолютное предпочтение государству.

Пожилые всегда чуть оптимистичнее представителей других возрастов оценивают социальные услуги религиозных организаций. При этом стоит отметить, что в большинстве случаев респонденты не обращались за услугами в религиозные организации и оценивают их умозрительно. По итогам опроса следует сделать вывод, что сами пожилые демонстрируют пассивное отношение к получаемой или запрашиваемой помощи и представляют социальную работу религиозных организаций в более традиционной парадигме, чем государственную.

\section{Заключение}

Социальная политика в отношении пожилых в современной России претерпела трансформации с начала 1990-х гг. и ориентирована сейчас в большей мере на эконмическую самостоятельность граждан старшего возраста, активное долголетие и реализацию социальной агентности 
в различных сферах жизнедеятельности. Вместе с тем социальное обслуживание пожилых остается наиболее традиционной сферой и демонстрирует многие стереотипы прежнего времени. Социальная работа с клиентами старшего возраста (государственная) основана на традиционной парадигме, ей свойственна меньшая гибкость по сравнению с оказанием социальных услуг другим, более ресурсным, клиентам. Негосударственная социальная работа развивается неравномерно, разные виды НКО представляют обычные формы заботы наряду с инновационными.

Социальная работа религиозных организаций демонстрирует более стереотипный взгляд на пожилого человека как пассивного получателя помощи, в риторике экспертов отсутствует обращение к ресурсам пожилых или возможности их активизации. Сами пожилые (потенциальные) клиенты, как правило, считают, что им должны оказывать помощь в любом случае. Они рассчитывают на сострадание и милосердие сотрудников религиозных организаций, а социально-экономические услуги предпочитают получать от государства, понимая его как главный ресурс помощи.

Развитие социальной работы религиозных организаций, скорее всего, будет продолжаться неспешными темпами, с сохранением глокализационной специфики российских конфессий и разрыва в возможностях отношений с властными структурами. Адаптация лучшей практики инноваций, в том числе, технологических, в социальной работе с пожилыми имеет реальные перспективы развития и становится дополнительной возможностью коммуникации для всех участников процесса помощи пожилым.

\section{Список источников}

АСИ (2016) Социальные услуги пожильм - в реестре и за его пределами. Доступно по ссылке: https://www.asi.org.ru/article/2016/01/20/sotsialnye-uslugi-pozhilym-vreestre-i-za-ego-predelami/ (дата обращения: 13 мая 2017).

Бодановская 3. Д., Гольдман Е. В. (2015) Независимая оценка некоммерческими организациями комплексных центров социального обслуживания населения СанктПетербурга как механизм повышения эффективности реализации социальной политики в отношении лиц пожилого возраста. Непрерывное образование и психическое здоровье: возможности для молодых и пожильх, Санкт Петербург, 24-25 апреля 2015 г. Доступно по ссылке: silveryears.ru/data/uploads/download/sbornik-konferenc.pdf (дата обращения: 19 мая 2017).

Григорьева И.А. (2005а) Приоритеты социальной политики: пожилые люди. Журнал социологии и сочиальной антропологии, (3): 130-145.

Григорьева И.А. (2005b) Социальное обслуживание пожилых и развитие сообществ: применим ли западный опыт в России. Отечественные записки, (3): 90-97.

Кононенко Р.В. (2013) Дилеммы профессионализации приходской социальной работы в государстве благосостояния. Журнал исследований социальной политики, 11 (3): 369-376. 
Любезнова Е., Орлова А., Сорочан Е. (2015) Как помогать просителям: работа иерковной социальной службы. М.: Лепта Книга.

Лянгасов С.И. (2015) Как мы подавали заявку в реестр поставщиков социальных услуг. Доступно по ссылке: http://edu-biz.org/2015/06/04/kak-my-popadali-v-reestrpostavshhikov-socialnyx-uslug/ (дата обращения: 17 мая 2017).

Минтруда РФ (2016) Информация об опыте работы субъектов Российской Федераичи по оказанию соииальных услуг населению с использованием негосударственных организаиий. Доступно по ссылке: www.rosmintrud.ru/docs/mintrud/.../Informatciya sotcobsluzhivanie_pozhilyh.doc (дата обращения: 13 мая 2017).

Распоряжение Правительства РФ (2008) О Концеепци долгосрочного социальноэкономического развития Российской Федерачии на период до 2020 года N 1662-р от 17.11.2008 г.

Распоряжение Правительства РФ (2016) Об утверждении Стратегии действий в интересах граждан старшего поколения в Российской Федераиии до 2025 года № 164-р от 05.02.2016 г.

Рондик И.Н. (2015) Поставщцики социальных услуг: реальность, перспективы, Кемерово, 2 декабря 2015 г. Доступно по ссылке: http://nko.economy.gov.ru/PortalNews/ $\operatorname{Read} / 2190$ (дата обращения: 19 мая 2017).

Садыков Р.А. (2015) Профессиональная культура негосударственной социальной работы. Е.Р. Ярская-Смирнова (ред.) Профессиональная культура работников соииальных служб: сочиально-антропологическое исследование. Москва: Вариант:240-255.

Саралиева З.Х., Балабанов С. С. (1999) Пожилой человек в Центральной России. Социологические исследования, (12): 54-64.

Федеральный закон (2013) Об основах сочиального обслуживания граждан в Российской Федеращии № 442-ФЗ от 28.12.2013 г.

Холявин А.О. (2015) Особенности участия НКО в обеспечении социальной поддержки пожилым людям в России. Непрерывное образование и психическое здоровье: возможности для молодых и пожильх, Санкт Петербург, 24-25 апреля 2015 г. Доступно по ссылке: silveryears.ru/data/uploads/download/sbornik-konferenc.pdf (дата обращения: 19 мая 2017).

Pfeiferová Š., Lux M., Dvořák T., Havlíková J., Mikeszová M., Sunega P. (eds.) (2013) Housing and Social Care for the Elderly in Central Europe. WP3: Main Findings Report. Доступно по ссылке: www.central2013.eu/fileadmin/user_upload/.../HELPS_Main_Findings_Report. pdf (дата обращения: 16 июня 2017). 


\section{THE ELDERLY}

\section{IN THE MODERN RUSSIAN SYSTEM OF SOCIAL WORK}

This article examines recent changes in social policy and social work in relation to older citizens in modern Russia. The main focus is on the transformation of social work with the elderly in the last four years, which is linked to growing contractual relations in social services and the participation of socially-oriented non-profit organizations in the competition for state subsidies. The study of non-state social work with respect to the elderly was conducted through consulting a variety of sources, including expert interviews with representatives of religious organizations on the provision of social services $(\mathrm{N}=59)$ from 2008-2013; surveys in Nizhny Novgorod based on quota sampling $(\mathrm{N}=1976)$ in 2013-2014; notes from conversations on the how the religious needs of clients in the provision of social services in state social institutions are accounted for $(\mathrm{N}=53$ ) in 2015-2016, and, finally, the authors' observations on social assistance provision to elderly religious organizations in Nizhny Novgorod, Moscow, Ukraine and Germany over the last twenty years. According to this research, the expectations of the elderly regarding the social services of state institutions and religious organizations are focused on passive assistance. Experts of religious organizations construct elderly clients as beneficiaries, ignoring their resources and any possibility of activation. Uneven lagging behind the ideology of social work from the benchmarks of social policy is noted. The main type of activity in state institutions revolves around the formation of a register of recipients and the implementation of social services. Non-commercial secular social organizations demonstrate a much wider range of social services and are ready to introduce innovations. Religious organizations traditionally refer the elderly to clients of social work and orient them toward passively receiving assistance.

Key words: elderly, social policy, social work, socially-oriented non-profit organizations, religious organizations

DOI: 10.17323/727-0634-2018-16-1-95-108

\section{References}

ASI (2016) Sotsial'nye uslugi pozhilym - v reestre i za ego predelami [Social Services for the Elderly - in the Registry and Beyond]. Availible at: https://www.asi.org.ru/article/2016/01/20/ sotsialnye-uslugi-pozhilym-v-reestre-i-za-ego-predelami/ (accessed 13 May 2017).

Bodanovskaya Z., Gol'dman E. (2015) Nezavisimaya otsenka nekommercheskimi organizatsiyami kompleksnykh tsentrov sotsial'nogo obsluzhivaniya naseleniya Sankt-Peterburga kak

Zaretkhan H.M. Saralieva - Doctor (History), Head of Department of General Sociology and Social work, National Research Nizhny Novgorod State University Named after N. I. Lobachevsky, Nizhny Novgorod, Russian Federation. Email: zara@fsn.unn.ru

Irina E. Petrova - Ph.D (Sociology), Associate Professor of General Sociology and Social Work, National Research Nizhny Novgorod State University Named after N. I. Lobachevsky, Nizhny Novgorod, Russian Federation. Email: irinapetrova@mail.ru 
mekhanizm povysheniya effektivnosti realizatsii sotsial'noy politiki $v$ otnoshenii lits pozhilogo vozrasta [Independent Evaluation by Non-Commercial Organizations of Complex Centers of Social Services for the Population of St. Petersburg as a Mechanism to Increase the Effectiveness of Social Policy Implementation in Relation to the Elderly]. Nepreryvnoe obrazovanie $i$ psikhicheskoe zdorov'e: vozmozhnosti dlya molodykh i pozhilykh, Sankt Peterburg, 24-25 aprelya 2015 g. Available at: silveryears.ru/data/uploads/download/sbornik-konferenc.pdf (accessed 19 May 2017).

Federal Law (2013) Ob osnovakh sotsial'nogo obsluzhivaniya grazhdan v Rossiyskoy Federatsii [On the Basis of Social Services for Citizens in the Russian Federation] No 442-FZ from 28.12.2013.

Grigor'eva I. (2005a) Prioritety sotsial'noy politiki: pozhilye lyudi [Priorities of Social Policy: the Elderly]. Zhurnal sotsiologii i sotsial'noy antropologii [The Journal of Sociology and Social Anthropology], (3): 130-145.

Grigor'eva I. (2005b) Sotsial'noe obsluzhivanie pozhilykh i razvitie soobshchestv: primenim li zapadnyy opyt v Rossii [Social Services for the Elderly and Community Development: Is the Western Experience Applicable in Russia?]. Otechestvennye zapiski [Notes of the Fatherland], (3): 90-97.

Kononenko R. (2013) Dilemmy professionalizatsii prikhodskoy sotsial'noy raboty v gosudarstve blagosostoyaniya [The Dilemmas of Professionalizing Parochial Social Work in the Welfare State]. Zhurnal issledovanii sotsial'noy politiki [TheJournal of Social policy Studies], 11 (3): 369-376.

Lyangasov S. (2015) Kak my podavali zayavku v reestr postavshchikov sotsial'nykh uslug [How Did We Apply to the Register of Social Service Providers]. Available at: http://edu-biz.org/2015/06/04/ kak-my-popadali-v-reestr-postavshhikov-socialnyx-uslug/ (accessed 17 May 2017).

Lyubeznova E., Orlova A., Sorochan E. (2015) Kak pomogat' prositelyam: rabota tserkovnoy sotsial'noy sluzhby [How to Help Petitioners: The Work of the Church Social Service]. Moscow: Lepta Kniga.

Mintruda R. (2016) Informatsiya ob opyte raboty sub"ektov Rossiyskoy Federatsii po okazaniyu sotsial'nykh uslug naseleniyu s ispol'zovaniem negosudarstvennykh organizatsiy [Information on the Experience of the Work of the Subjects of the Russian Federation in the Provision of Social Services to the Population Using Non-Governmental Organizations]. Available at: www.rosmintrud.ru/docs/mintrud/.../Informatciya_sotcobsluzhivanie_pozhilyh.doc (accessed 13 May 2017).

Government of the Russian Federation (2008) O Kontseptsii dolgosrochnogo sotsial'no-ekonomicheskogo razvitiya Rossiyskoy Federatsii na period do 2020 goda [On the Concept of Long-Term Social and Economic Development of the Russian Federation for the Period to 2020] N 1662-r from 17.11.2008.

Government of the Russian Federation (2016) Ob utverzhdenii Strategii deystviy v interesakh grazhdan starshego pokoleniya v Rossiyskoy Federatsii do 2025 goda [On the Approval of the Strategy of Action for the Benefit of Citizens of the Older Generation in the Russian Federation until 2025] № 164-r from 05.02.2016.

Pfeiferová Š., Lux M., Dvořák T., Havlíková J., Mikeszová M., Sunega P. (eds.) (2013) Housing and Social Care for the Elderly in Central Europe. WP3: Main Findings Report. Available at: www.central2013.eu/fileadmin/user_upload/.../HELPS_Main_Findings_Report.pdf (accessed 16 June 2017).

Rondik I. N. (2015) Postavshhiki social'nyh uslug: real'nost', perspektivy, Kemerovo, 2 dekabrja 2015 [Providers of Social Services: Reality, Prospects, Kemerovo, December 2, 2015]. Available at: http://nko.economy.gov.ru/PortalNews/Read/2190 (accessed 19 May 2017).

Sadykov R.A. (2015) Professional'naya kul'tura negosudarstvennoy sotsial'noy raboty [Professional Culture of Non-State Social Work]. E. Yarskaya-Smirnova (ed.) Professional'naya kul'tura rabotnikov sotsial'nykh sluzhb: sotsial'no-antropologicheskoe issledovanie [Professional Culture of Social Workers: A Socio-Anthropological Study]. Moscow: Variant:240-255.

Saralieva Z., Balabanov S. (1999) Pozhiloy chelovek v Tsentral'noy Rossii [An Elderly Person in Central Russia]. Sotsiologicheskie issledovaniya [Sociological Studies], (12): 54-64. 